\title{
Correction to: On the Convergence of Asynchronous Parallel Iteration with Unbounded Delays
}

\author{
Zhimin Peng1 ${ }^{1}$ Yangyang $\mathrm{Xu}^{2} \cdot \mathrm{Ming}_{\mathrm{Yan}^{3}} \cdot$ \\ Wotao Yin $^{1}$ (D)
}

(C) The Author(s) 2018, corrected publication June 2018

\section{Correction to: J. Oper. Res. Soc. China https://doi.org/10.1007/s40305-017-0183-1}

The article "On the Convergence of Asynchronous Parallel Iteration with Unbounded Delays", written by Zhimin Peng, Yangyang Xu, Ming Yan, Wotao Yin was originally published electronically on the publisher's Internet portal (currently SpringerLink) on 9th December 2017 without open access.

With the author(s)' decision to opt for Open Choice, the copyright of the article changed on 12th June 2018 to (C) The Author(s) 2018 and the article is forthwith distributed under the terms of the Creative Commons Attribution 4.0 International License (http://creativecommons.org/licenses/by/4.0/), which permits use, duplication, adaptation, distribution and reproduction in any medium or format, as long as you give appropriate credit to the original author(s) and the source, provide a link to the Creative Commons license and indicate if changes were made.

The original article can be found online at https://doi.org/10.1007/s40305-017-0183-1.

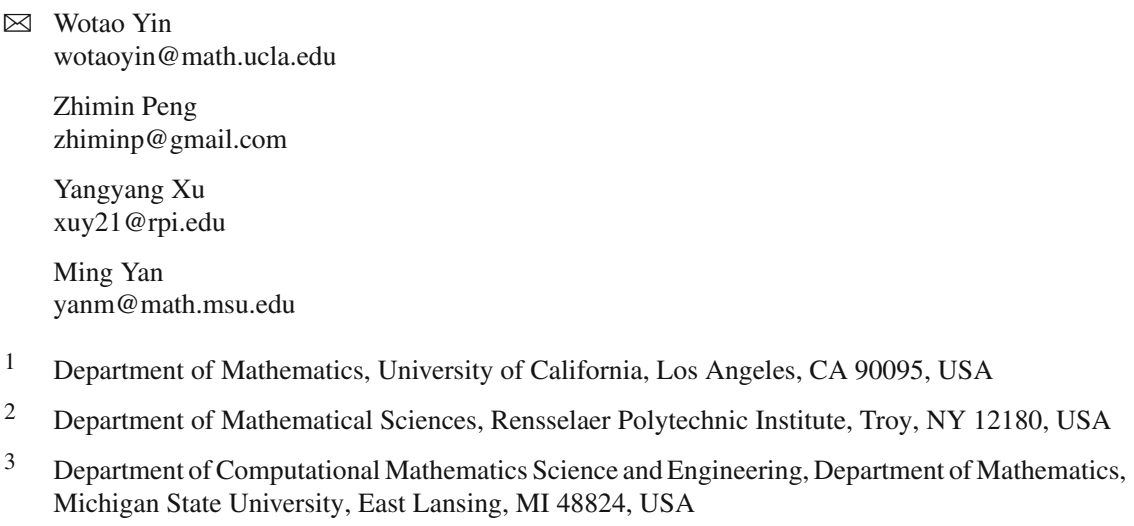

